\title{
ANALYSIS OF CIRCULAR DISC ANTENNA USING DEFECTIVE GROUND PLANE
}

\author{
Brajesh Kumar Gupta ${ }^{1}$, Sumita Mishra ${ }^{2}$ \\ ${ }^{I}$ M.tech Student, Department of Electronics \& Comm. Engg., Amity University, Lucknow \\ ${ }^{2}$ Sr. Lecturer Department of Electronics \& Comm. Engg., Amity University, Lucknow
}

\begin{abstract}
Satellite communication and Wireless communication has been developed rapidly in the past decades and it has already a dramatic impact on human life. In the present time in commercial and government communication system has been develop low cost, minimal weight, minimal size, low profile antenna, the capable of maintaining the performance over a large spectrum of frequencies. This paper emphasizes the use of Defected Ground Structure (DGS) technique in microstrip patch antenna. This circular disc or patch antenna is designs are simulated using the IE3D software. And try to find out the different-different condition the maximum gain output and bandwidth. The simulated and measured results are in close agreement which validates the role of the designed antenna for operation in wireless applications from $5-15 \mathrm{GHz}$. A comparison is drawn between the performances of the antennas in terms of gain, return loss, VSWR of the antennas.
\end{abstract}

Keywords: Broad band, coplanar waveguide, Defected ground structure, Circular patch antenna.

****

\section{INTRODUCTION}

As the process of miniaturization of devices is in full swing, antennas cannot remain as standalone devices. Compact designs have to be implemented to cope with the demands of the industry. In today's scenario of wireless system and booming demand for a variety of new wireless application, there is great need to design broadband antennas which offers complete package of minimal cost, light weight and high performance to cover a wide frequency range. With increasing requirements for personal and mobile communications the demand for smaller and low profile antennas has brought the microstrip antennas to forefront. Present time is witnessing a very rapid growth of wireless communications, for which compact antennas are in strong demand as they can be easily integrated with wireless devices. For good antenna performance, broadband antennas are in strong demand as they provide access to various wireless communications in single time. The care should also be taken to protect microstrip antennas from dielectric and surface wave losses. Surface wave occurs due to the trapping of total available radiated power along the surface of the antenna substrate [4]. These waves reduce the antenna gain, efficiency and bandwidth. All these problems can be removed by using DGS structure in microstrip patch antennas which supports multiband that can operate at different frequencies for one device [6]. The antenna is designed with dielectric substrate having dimensions of $18 \times 20 \times 1.6 \mathrm{~mm}$ and circular patch of radius $5 \mathrm{~mm}$. Circular shape slots are created in the ground plane as defects. The CPW feed is used as it exhibits less dispersion, low radiation loss and uniplanar configuration [9]. The proposed antenna finds its application in WLAN IEEE 802.11 and X-band. Depending upon the geometry, design and size of the defects in the ground plane, DGS produces different cut off frequencies and $-10 \mathrm{~dB}$ bandwidth

\section{ANTENNA STRUCTURE}

Figure 1, Figure 2 shows the geometry of the proposed circular microstrip patch antenna with and without DGS together with its geometrical dimensions. The proposed antenna structure is a circular patch of radius $5 \mathrm{~mm}$. A circular slot is etched in the patch. The main radiation elements of the antenna, which are etched on the ground plane, are circular shape defects which make the antenna to achieve better gain. Table 1 shows the optimized design parameters obtained for the proposed patch antenna. These design parameters are obtained by parametric analysis performed on various dimensions of the antenna in HFSS. The F R 4 e p o x y dielectric substrate with dielectric permittivity ' $\mathrm{kr}$ ' of 4.4, dielectric loss tangent of 0.02 and thickness ' $h$ ' of $1.6 \mathrm{~mm}$ has been used in this research. The metal patch has been printed on one side of the dielectric substrate where as the other side of the dielectric substrate does not have metallic printing this makes the geometry truly planar. These monopoles can be integrated with other components on printed circuit board, have reduced size on dielectric substrate, are without backing ground plane and are easy ton fabricate. Printed antennas, commonly fabricated on FR4 substrate, are 
very cost effective, which is ideally suited for UWB technology-based low-cost systems [8].
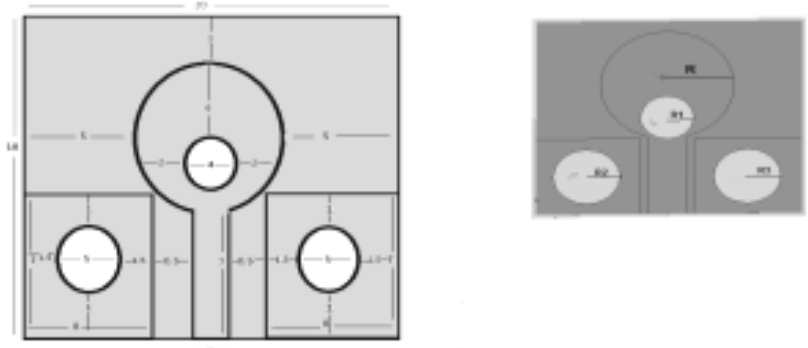

Fig 1 (a): Geometry of circular patch antenna with DGS.
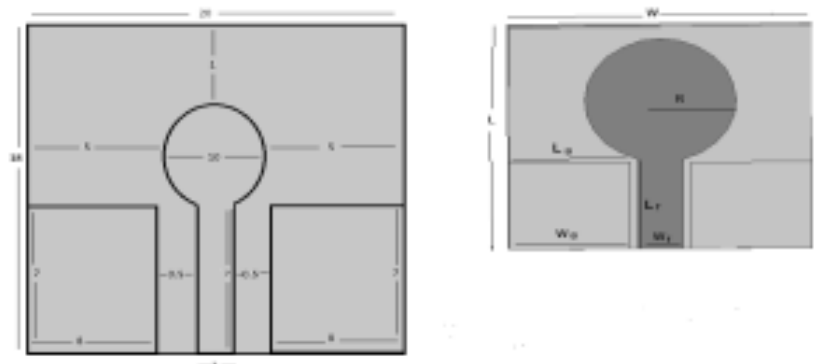

Fig 1 (b): Geometry of circular patch antenna without DGS.

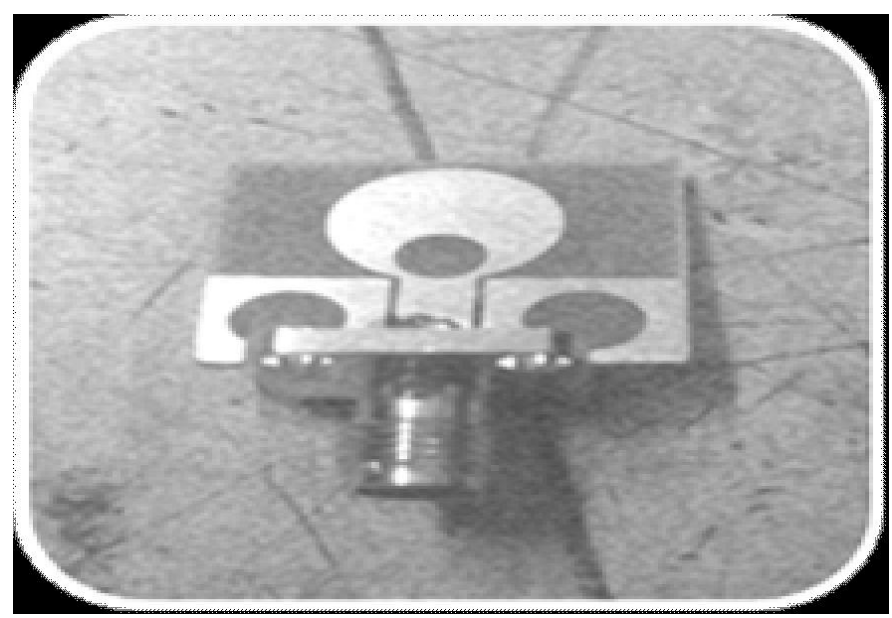

Fig 2: Fabricated antenna without Defected Ground Structure.

\section{SIMULATION RESULTS}

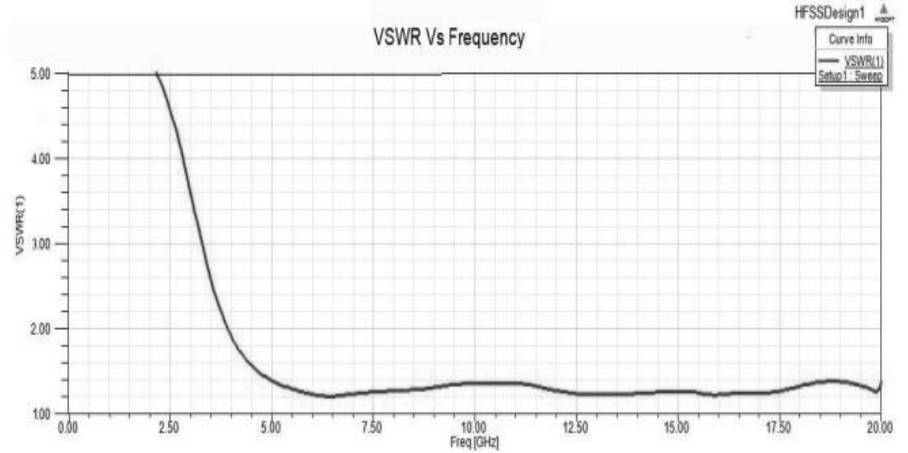

Fig 3: VSWR of the circular patch antenna without DGS

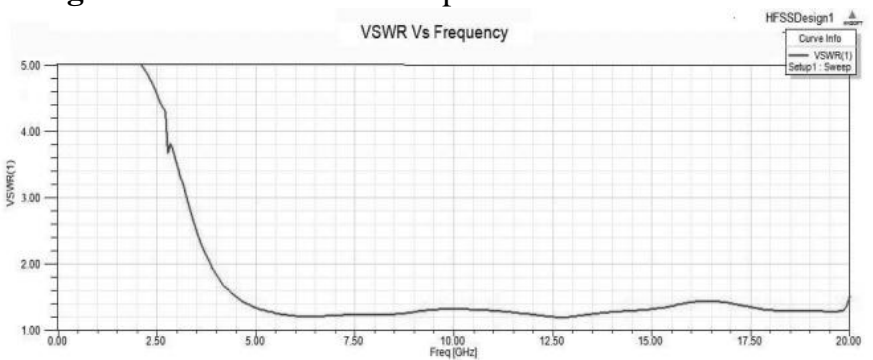

Fig 4: VSWR of the circular patch antenna with DGS

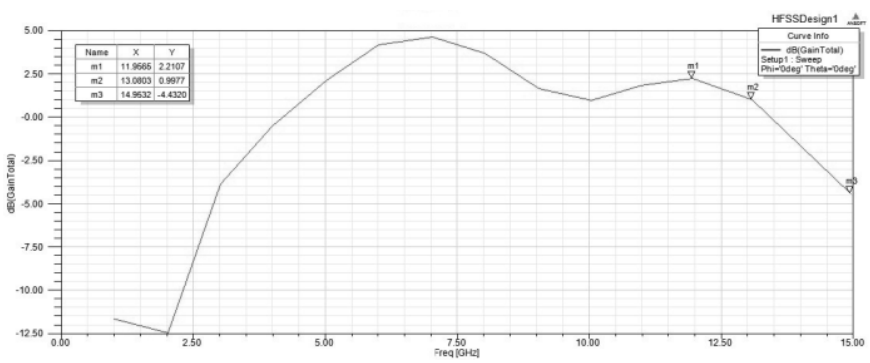

Fig 5: Gain of the circular patch antenna without DGS

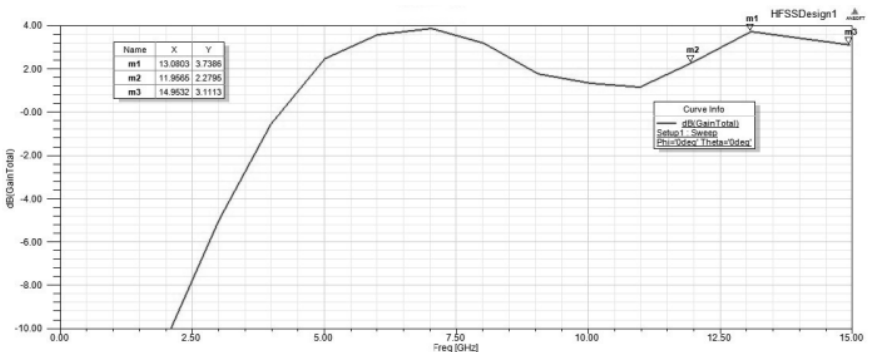

Fig 6: Gain of the circular patch antenna with DGS.

\section{CONCLUSIONS}

It can be concluded from the above analysis that both the antennas will meet the specifications of WLAN IEEE 802.11 and X-band applications. Due to enhancement of gain in design 2 using DGS structure this antenna will significantly suppress potential interference in existing systems i.e. WLAN applications, X- band [Zulkifli (2010)] uplink frequency band (for sending modulated signals) as from 7.9 to $8.4 \mathrm{GHz}$ and for downlink frequency band (for receiving signals) as 7.25 ton $7.75 \mathrm{GHz}, \mathrm{X}$ - band applications including short range tracking, missile guidance, marine, radar and airborne intercept. It will be 
useful for radar communication which ranges roughly from $8.29 \mathrm{GHz}$ to $11.4 \mathrm{GHz}$. The feasibility of the design is proved by simulations and testing.

\section{FUTURE SCOPE}

This antenna can be considered as a potential candidate for cost effective communication applications. Below are the suggestions for future scope:

(i) The proposed antenna structure can further be modified for increasing the gain.

(ii) We can make use of different antenna structure which can be integrated by introducing slits in the patch in order to improve the performance of the antenna.

(iii) The design can be modified further by changing antenna dimensions on some different substrate and introducing different shapes as defective ground structure in ground plane.

\section{REFERENCES}

[1]. D. M. Pozar, "Microstrip Antennas", Proceedings of the IEEE. Volume 80, Issue 1, January 1992, pp. 79 -91.

[2]. M. Mahdi Honari, Abdolali Abdipour and Gholamreza Moradi, "Bandwidth and Gain Enhancement of an Aperture Antenna with Modified Ring Patch", IEEE ANTENNAS AND WIRELESS PROPAGATION LETTERS, vol. 10, pp. 14131416, 2011.

[3]. D. Ahn, J. S. Park, C. S. Kim, J. Kim, Y. Qian, and T. Itoh, "A design of the low-pass filter using the novel microstrip defected ground structure," IEEE Trans. Microwave Theory Tech., Vol. 49, pp. 86-93, Jan. 2001.

[4]. C. A. Balanis, "Antenna Theory: Analysis and Design", 2nd Ed. New York: John Wiley and Sons. 1997, pp. 720-784.

[5]. X.-C. Lin and L.-T. Wang, "A wideband CPW-fed patch antenna with defective ground plane," IEEE Antennas and Propagation Society International Symposium, Vol. 4, pp.b 3717-3720, 2004..

[6]. H. Liu, Z. Li, X. Sun, and J. Mao "Harmonic Suppression with Photonic Bandgap and Defected Ground Structure for a Microstrip Patch Antenna", IEEE Microwave and Wireless Components Letters, vol. 15, no. 2, pp. 55-56, 2005.

[7]. F. Y. Zulkifli, E. T. Rahardjo, and D. Hartanto "Mutual Coupling Reduction using Dumbbell Defected Ground Structure for Multiband Microstrip Antenna Array", Progress In Electromagnetics Research Letters, vol. 13, pp. 29-40, 2010.

[8] .K. P. Ray, "Design Aspects of printed Monopole Antennas for Ultra-Wide Band Applications," Hindawi Publishing Corporation, International Journal of Antennas and Propagation, Volume 2008, Article ID 713858, doi:10.1155/2008/713858. 